\title{
NÍVEIS DE CÉLULAS SOMÁTICAS SOBRE O PERFIL FÍSICO-QUÍMICO DO LEITE EM PÓ INTEGRAL
}

\author{
SOMATIC CELLS LEVEL ON THE PHYSICOCHEMICAL \\ PROFILE OF POWDERED MILK
}

\author{
Karyne Oliveira Coelho ${ }^{1 *}$ \\ Lourival Marques Brandão1 \\ Claudia Peixoto Bueno ${ }^{1}$ \\ Camila Silveira Melo ${ }^{1}$ \\ Osvaldo José da Silveira Neto ${ }^{1}$ \\ ${ }^{1}$ Universidade Estadual de Goiás, São Luís de Montes Belos \\ *Autora para correspondência - karyne.coelho@ueg.br
}

\begin{abstract}
Resumo
Objetivou-se, com a realização deste trabalho, avaliar o efeito do nível de células somáticas (CCS) no leite sobre o perfil físico-químico do leite em pó integral. No período de janeiro de 2010 a junho de 2011, foram analisadas sete amostras de leite cru e do respectivo leite em pó produzido em uma indústria laticinista do Oeste Goiano. O leite cru foi analisado quanto à contagem de células somáticas e o leite em pó quanto às características físico-químicas: acidez, umidade, proteína e gordura. Foram avaliados dois tratamentos, sendo: leite em pó produzido com leite contendo CCS $\leq 400$ mil céls/ $\mathrm{mL}$ e o leite em pó elaborado com CCS $>400 \mathrm{mil}$ céls $/ \mathrm{mL}$. O delineamento experimental foi em blocos aleatórios. Na análise estatística, utilizou-se a análise de variância seguida do teste de Tukey, considerando-se $\mathrm{p}<0,05$ como probabilidade mínima aceitável para diferença entre as médias. O leite em pó elaborado com matéria prima com CCS superior a 400 mil céls $/ \mathrm{mL}$ apresentou concentração menor de proteína e maior de umidade. Considerando os tratamentos avaliados, pode-se afirmar que, para a obtenção de leite em pó com qualidade satisfatória, torna-se necessária a utilização de um leite com CCS inferior a 400 mil céls. $/ \mathrm{mL}$.
\end{abstract}

Palavras-chave: mastite-subclínica; proteína; qualidade; umidade.

\begin{abstract}
The objective of this study was to evaluate the level of somatic cells (SCC) on the physicalchemical profile of powdered milk. From January 2010 to June 2011, we analyzed seven raw milk samples and the respective powdered milk, totaling 14 samples from an industry in São Luís de Montes Belos-GO. Raw milk was analyzed for somatic cell counting and powdered milk for physical and chemical characteristics: acidity, moisture, protein, and fat. Two treatments were evaluated: powdered milk made from milk containing SCC $\leq 400,000$ cells $/ \mathrm{mL}$ and powdered milk prepared with SCC $>400,000$ cells $/ \mathrm{mL}$. The experimental design was in randomized blocks. For the statistical analysis we used analysis of variance, followed by Tukey test, considering $\mathrm{p}$ $<0.05$ as the minimum acceptable probability for the difference between means. The powdered milk prepared with raw material with SCC superior to 400,000 cells $/ \mathrm{mL}$ presented lower protein and higher humidity content. Considering the treatments, we can state that to obtain powder milk satisfactorily, it is necessary to use milk with SCC lower than 400,000 cells $/ \mathrm{mL}$.
\end{abstract}

Keywords: protein; quality; subclinical mastitis; umidity.

Enviado em: 10 fevereiro 2012

Aceito em: 28 setembro 2016 


\section{Introdução}

O leite, por ser um alimento perecível necessita de conservação, que se dá por diferentes técnicas, destacando-se a refrigeração, a concentração ou a secagem. O leite em pó é um produto obtido por meio de um processo tecnológico de desidratação do leite de vaca integral, desnatado ou semidesnatado, sendo que a gordura é ajustada a cada tipo de apresentação. O produto deve apresentar em seu rótulo todas as informações nutricionais e gerais estabelecidas pela Resolução da Diretoria Colegiada (RDC) $n^{\circ} 359 / 03^{(1)}$, além das informações exigidas pela RDC $n^{\circ} 360 / 03^{(2)}$.

O leite em pó apresenta vantagens em relação ao leite fluido, como por exemplo, a facilidade de armazenamento e de transporte. Além disso, permite melhor controle da política comercial e do mercado consumidor, principalmente, no período de entressafra, quando o volume produzido diminui em até $35 \%$, garantindo assim o suprimento de leite durante o período de $\operatorname{seca}^{(3,4)}$.

Entre os lácteos comercializados internacionalmente, o leite em pó é o produto de maior volume de transação comercial ${ }^{(4)}$. O Brasil se destaca como um dos maiores produtores de leite em pó integral, bem como a Nova Zelândia, enquanto que os Estados Unidos e a França são os maiores produtores de leite em pó desnatado. Visando à consolidação do setor lácteo, a fim de se conquistar o mercado não só internamente, mas também internacionalmente, faz-se necessário investimento no que diz respeito à qualidade.

Neste sentido, Foppa et al. ${ }^{(5)}$ ressaltaram que a qualidade do leite em pó pode ser influenciada por diversos fatores, sobretudo, a qualidade da matéria prima. Becker et al. ${ }^{(6)}$ destacaram que se deve observar a Contagem Bacteriana Total (CBT), Contagem de Células Somáticas (CCS), fatores físicoquímicos e os procedimentos ligados ao processamento do leite em pó, ou seja, o resfriamento e estocagem do leite cru, padronização e pasteurização, concentração, secagem, separação ar/pó e envase.

Portanto, a qualidade do leite é fator fundamental para o sucesso das empresas relacionadas com o produto. Os consumidores estão cada vez mais exigindo produtos de melhor qualidade e, por isso, todos os esforços devem ser direcionados no sentido de atender esta demanda. Dentre os fatores relacionados com a qualidade do leite está a mastite. A mastite é um processo inflamatório do úbere, acompanhado da redução de secreção de leite e mudança de permeabilidade da membrana que separa o leite do sangue ${ }^{(7)}$.

Destaca-se que vários fatores podem causar alterações nas propriedades físicas e químicas do leite em pó integral, reduzindo sua vida-de-prateleira e, assim, seu valor comercial. Porém, os principais fatores envolvidos na deterioração da qualidade do produto são a absorção de umidade, resultando na aglomeração do produto, e a oxidação lipídica ${ }^{(8,9)}$.

No que se refere particularmente à qualidade da matéria prima, destaca-se que o aumento na CCS associa-se a alterações nas características físico-químicas do leite. Neste caso, observam-se diminuição da concentração de caseína, gordura, cálcio, fósforo e lactose, aumento dos ácidos graxos livres de cadeia curta e incremento na atividade proteolítica e lipolítica do leite oriundos de vacas com mastite ${ }^{(7,10)}$. Estes fatores relacionam-se diretamente à qualidade do produto manufaturado: no caso, o leite em pó.

Ressalta-se que, para o controle da qualidade do leite em pó, utilizam-se as normas e procedimentos contidos no regulamento técnico de identidade e qualidade, que se baseia em padrões microbiológicos e físico-químicos. Quanto aos aspectos físico-químicos, o regulamento determina a classificação do leite em pó por conteúdo de matéria gorda em: integral (maior ou igual a 26,0\%), parcialmente desnatado (entre 1,5 a $25,9 \%$ ) e desnatado (menor que $1,5 \%)^{(11)}$.

Diante do exposto objetivou-se, com a realização do presente trabalho, avaliar a influência do nível de células somáticas (CCS) sobre o perfil físico-químico do leite em pó integral. 


\section{Material e métodos}

No período de janeiro de 2010 a junho de 2011, foram analisadas sete amostras de leite cru e do respectivo leite em pó integral (totalizando 14 amostras), em uma indústria laticinista da região de São Luís de Montes Belos, GO. O leite cru foi analisado quanto à contagem de células somáticas e o leite em pó quanto às características físico-químicas, conforme metodologia descrita pela Instrução Normativa $68^{(12)}$.

Foram avaliados dois tratamentos, sendo: leite em pó produzido com leite contendo CCS $\leq 400$ mil céls/mL (Padrão de CCS previsto para 2016 pela IN 62 de Brasil ${ }^{(13)}$ ) e o leite em pó produzido com CCS $>400$ mil céls $/ \mathrm{mL}$.

Todas as análises foram realizadas em triplicata, conforme procedimento. A acidez titulável do leite em pó foi determinada por meio da titulação das amostras com solução de hidróxido de sódio $(\mathrm{NaOH})$ N/9 (solução Dornic), tendo como indicador solução alcoólica de fenolftaleína a 1,0\%. Os resultados foram expressos em graus Dornic $\left({ }^{\circ} \mathrm{D}\right)^{(14)}$. Para a CCS do leite utilizou-se o equipamento Fossomatic 500 Basic $^{\circledR}$ (Foss Electric A/S. Hillerod, Denmark) cujo princípio analítico baseia-se na citometria de fluxo. Utilizou-se o método modificado do ácido butirométrico Van-Gulik para determinar a gordura do leite em pó, descrito por Brasil ${ }^{(14)}$, sendo o teor de gordura no extrato seco (G.E.S.) calculado segundo a equação:

$$
G E S=\frac{(10 \times \% G)}{\% E S T}
$$

O extrato seco total (EST) do leite em pó foi determinado de acordo com a $\mathrm{AOAC}^{(1)}$, metodologia 925.23, sendo a umidade calculada pela equação: $U(\%)=100 \%$ - EST(\%). No que concerne ao Nitrogênio Total (NT) empregou-se o método de Kjeldahl, conforme AOAC 991.20 ${ }^{(15)}$, sendo a proteína total calculada por meio da multiplicação da porcentagem de NT por 6,38.

Para verificar o efeito da qualidade da matéria prima "leite cru", ou seja, da CCS, sobre os parâmetros físico-químicos analisados no leite em pó, foi realizada a Análise de Variância dos dados e para a comparação de médias, o teste de Tukey a 5\% de significância. Os resultados obtidos foram tabulados e contrastados à legislação vigente, a fim de se verificar a ocorrência de amostras em desacordo com os padrões.

\section{Resultados e Discussão}

Em relação à composição do leite cru e em pó, observou-se redução significativa nos teores de proteína e gordura com o aumento da CCS, acompanhado do aumento de umidade, entre os tratamentos avaliados (Tabela 1).

No leite de vacas com mastite subclínica observa-se o aumento de enzimas proteolíticas, especialmente, a plasmina e seu precursor inativo o plasminogênio. Além dessas, outras enzimas originadas das células somáticas e dos leucócitos contribuem para a atividade proteolítica no leite ${ }^{(7)}$; portanto, tal comportamento deve estar relacionado a um teor menor de proteína no leite em pó produzido com CCS superior, observado neste estudo. Considine et al. ${ }^{(10)}$, ao estudarem a catepsina-G que é uma das principais proteases liberadas pelos polimorfonucleares, verificaram a capacidade da enzima de hidrolisar as $\alpha_{s 1}$ e $\beta$-caseínas com produção de peptídeos similares aos liberados pela plasmina e concluíram que a catepsina-G pode contribuir de maneira significativa para a proteólise que ocorre no leite com alta CCS. 
Tabela 1. Valores médios $(\mu)$ e desvio padrão $(\sigma)$ de proteínas, umidade, gordura e acidez do leite em pó produzido com leite cru contendo CCS $\leq 400 \mathrm{mil}$ céls $/ \mathrm{mL}$ e CCS $>400 \mathrm{mil} \mathrm{céls} / \mathrm{mL}$

\begin{tabular}{lcc}
\hline \multicolumn{1}{c}{ Parâmetros Avaliados } & $\mathbf{C C S} \leq \mathbf{4 0 0}$ mil céls $/ \mathbf{m L}$ & $\mathbf{C C S}>\mathbf{4 0 0}$ mil céls $/ \mathbf{m L}$ \\
& $\boldsymbol{\mu} \pm \boldsymbol{\sigma}$ & $\boldsymbol{\mu} \pm \boldsymbol{\sigma}$ \\
\hline Proteínas $(\% \mathrm{~m} / \mathrm{m})$ & $26,33 \pm 2,70^{\mathrm{a}}$ & $24,45 \pm 3,11^{\mathrm{b}}$ \\
Umidade $(\% \mathrm{~m} / \mathrm{m})$ & $2,46 \pm 0,71^{\mathrm{a}}$ & $3,17 \pm 1,56^{\mathrm{b}}$ \\
Gordura $(\% \mathrm{~m} / \mathrm{m})$ & $26,70 \pm 0,57^{\mathrm{a}}$ & $25,9 \pm 1,95^{\mathrm{b}}$ \\
Acidez $(\mathrm{mL} \mathrm{NaoH} 0,1 \mathrm{~N} / 10 \mathrm{~g})$ & $16,86 \pm 0,71^{\mathrm{a}}$ & $17,3 \pm 1.56^{\mathrm{a}}$ \\
\hline CCS: Contagem de células somáticas; Letras iguais na mesma linha não diferem entre $s i \mathrm{p} / \mathrm{p}>0,05$.
\end{tabular}

Em relação à umidade, observou-se um comportamento proporcional, ou seja, conforme o aumento da CCS teve-se um aumento do teor de umidade no leite em pó, para R: 0,62. Tal fato pode ter ocorrido devido à ação de enzimas de origem leucocitária, ou seja, da CCS, que agiram sobre a proteína, por um processo denominado proteólise. Sabe-se que tal processo ocorre com a liberação de moléculas de água que, consequentemente, interferiu no teor de umidade do produto final.

Maia e Golgher ${ }^{(16)}$ relataram que a faixa ótima para a umidade do leite em pó integral é entre $2 \%$ e 3\%, pois, em valores inferiores, a gordura se torna mais suscetível a reações de oxidação e em valores superiores são propiciadas reações de cristalização de lactose, desenvolvimento de odores, escurecimento, insolubilização proteica, aumento de acidez, produção de gás carbônico, entre outros. Deste modo, o leite em pó elaborado com leite cru com CCS superior a 400 mil céls $/ \mathrm{mL}$ torna-se um produto susceptível a alterações sensoriais.

Quanto aos lipídeos, também se observou uma menor concentração do componente no leite em pó produzido com CCS superior a $400 \mathrm{mil} \mathrm{céls} / \mathrm{mL}$. Neste sentido, Coelho et al. ${ }^{(7)}$ ressaltaram que o percentual de gordura se reduz como resultado da infecção do úbere. No entanto, quando a produção de leite é reduzida em maior proporção que a síntese, o teor de gordura aumenta, proporcionalmente.

As características físico-químicas de gordura, acidez e umidade das amostras analisadas logo após o envase apresentaram valores diferenciados quanto à conformidade com a legislação vigente, conforme Portaria $\mathrm{n}^{\mathrm{0}} 146$ do Ministério da Agricultura, Pecuária e Abastecimento ${ }^{(17)}$. Reitera-se que para o leite em pó integral a gordura deve ser superior a $26 \%$, a acidez no máximo $18^{\circ} \mathrm{D}$ e a umidade máxima de $3,5 \%$ (Tabela 2 ).

Tabela 2. Percentual de amostras de leite em pó em desacordo com a legislação vigente, nos quesitos: gordura, acidez, umidade, do leite em pó produzido com leite contendo $\mathrm{CCS} \leq 400 \mathrm{mil}$ céls $/ \mathrm{mL}$ e CCS $>400 \mathrm{mil}$ céls $/ \mathrm{mL}$

\begin{tabular}{lcc}
\hline \multicolumn{1}{c}{ Parâmetros } & $\begin{array}{r}\text { CCS } \leq \mathbf{4 0 0} \text { mil } \\
\text { céls } / \mathbf{m L}\end{array}$ & $\begin{array}{c}\mathbf{C C S}>\mathbf{4 0 0} \text { mil } \\
\text { céls } / \mathbf{m L}\end{array}$ \\
\hline Umidade $(\% \mathrm{~m} / \mathrm{m})$ & $14,3 \%$ & $42,8 \%$ \\
Acidez $(\mathrm{mL} \mathrm{NaoH} 0,1 \mathrm{~N} / 10 \mathrm{~g})$ & $0 \%$ & $0 \%$ \\
Gordura $(\% \mathrm{~m} / \mathrm{m})$ & $0 \%$ & $14,3 \%$ \\
\hline
\end{tabular}

Madi et al. ${ }^{(18)}$ indicaram que a umidade crítica do leite em pó integral é de 5,0\%, a partir da qual o produto inicia alterações indesejáveis, como deterioração microbiana e aglomeração. Esses autores apontaram, ainda, que se deve buscar a obtenção de um produto com umidade baixa após envase, porque, no período de armazenamento, o mesmo poderá absorver água o que determinará mudanças quanto à qualidade. Neste sentido, torna-se necessária a monitorizarão da CCS, pois se percebe (Tabela 2) que ocorreu um percentual significativo de amostras com resultados superiores ao preconizado na legislação vigente ${ }^{(11)}$. 
Os dados obtidos no presente trabalho são superiores aos encontrados por uma avaliação realizada pelos analistas do INMETRO ${ }^{(19)}$, os quais encentraram um percentual de $25 \%$ de amostras de leite em pó comercializadas em São Paulo em desacordo com a legislação vigente, no que diz respeito ao perfil físico-químico, acidez e lipídeo.

\section{Conclusões}

Verificou-se a alteração de três parâmetros, proteína, gordura e umidade, em leite em pó produzido com leite contendo CCS superior a $400 \mathrm{mil} \mathrm{céls} / \mathrm{mL}$; portanto, torna-se necessário o controle efetivo dos procedimentos relacionados aos aspectos sanitários dos rebanhos leiteiros, para que se consiga a produção de um leite em pó de qualidade.

\section{Referências}

1. Brasil. Agência Nacional de Vigilância Sanitária. RDC n. 359, de 23 de dezembro de 2003. Aprova regulamento técnico de porções de alimentos embalados para fins de rotulagem nutricional. Diário Oficial da República Federativa do Brasil, Brasília, n. 251, 26 de dezembro de 2003, Seção 1, p. 28. 1. Portuguese.

2. Brasil. Agência Nacional de Vigilância Sanitária. RDC n. 360, de 23 de dezembro de 2003. Aprova regulamento técnico sobre rotulagem nutricional de alimentos embalados, tornando obrigatória a rotulagem nutricional. Diário Oficial da República Federativa do Brasil, Brasília, n. 251, 26 de dezembro de 2003, Seção 1, p. 33. 1. Portuguese.

3. Campos LR, Treptow RO, Soares GJD. Influência da inertização com nitrogênio na vida-de-prateleira de leite em pó integral acondicionado em embalagens metalizadas flexíveis. Revista Brasileira de Agrociências, 1998; 2(2): 30-137.

4. Carvalho, GR. O Comércio Internacional de lácteos - O comércio Internacional de Leite em Pó. 1 st ed. Juiz de Fora: Templo, 2008. p. 53.

5. Foppa T, Ferrareze CK, Casgrande J, Koch PA. Análises físico-químicas do leite em pó comparado ao leite UHT. Agora: Revista de Divulgação Científica, 2009; 16(1): 38-43.

6. Becker TA, Negrelo IF, Racoulte F, Drunkler DA. Avaliação da qualidade sanitária de leite integral informal, pasteurizado, UHT e em pó comercializados na cidade de Medianeira e Serranópolis do Iguaçu - Paraná. Semina: Ciências Agrárias, 2010; 31(3):707-716.

7. Coelho KO, Mesquita AJ, Machado PF, Oliveira NA, Souza CM, Meyer PM. Níveis de células somáticas sobre a proteólise do queijo Mussarela, Revista Brasileira de Saúde e Produção Animal, 2012;13(3): 682-693.

8. Maia ABRA, Golgher M. Parâmetros par avaliação da qualidade de reconstituição do leite em pó desidratado em secador de aspersão. Boletim SBCTA, 1983; 17 (3): 235-254.

9. Mazal G, Vianna PCB, Santos MV, Gigante ML. Effect of Somatic Cell Count on Prato Cheese Composition. Journal of Dairy Science. 2007;90 (1):630-636.

10. Considine T, Kelly AL, Healy A, Mcsweeney PLH. Hydrolysis of bovine caseins by cathepsin B, a cysteine protease indigenous to milk. International Dairy Journal, 2004; 14 (2): 117-124.

11. Brasil. Ministério da Agricultura, Pecuária e Abastecimento. Portaria no. 146 de 07 de março de 1996. Regulamento técnico de identidade e qualidade de leite em pó. Diário Oficial da União, 1996. Mar. 11; Seção 1. Portuguese.

12. Brasil. Ministério da Agricultura, Pecuária e Abastecimento. Instrução Normativa $n^{\circ}$. 68, de 12 de dezembro de 2006. Oficializa os Métodos Analíticos Oficiais Físico-Químicos, para Controle de Leite e Produtos Lácteos, em conformidade com o anexo desta Instrução Normativa, determinando que sejam utilizados nos 
Laboratórios Nacionais Agropecuários. Diário Oficial [da] República Federativa do Brasil, Brasília, 14 dez. 2006, p. 08, Seção 1. Portuguese.

13. Brasil. Ministério da Agricultura Pecuária e Abastecimento. Instrução Normativa Número 62 de 29 de dezembro de 2011. Dispõe sobre regulamentos técnicos aplicados ao leite cru e pasteurizado. Diário Oficial da União, Brasília, Seção 1, n.83, p.13-22, Dez. 29, 2011. Portuguese.

14. Brasil. Ministério da Agricultura, Pecuária e Abastecimento. Instrução Normativa no. 22 de 14 de abril de 2003. Métodos analíticos oficiais físico-químicos para o controle de leite e produtos lácteos. Diário Oficial da União, 2003b. Mai. 02; Seção 1. Portuguese.

15. Association of official analytical chemists (AOAC). Official methods of analysis of AOAC international. 16st ed. Washington: AOAC, 1995. Inglês.

16. Maia ABRA, Golgher M. Parâmetros par avaliação da qualidade de reconstituição do leite em pó desidratado em secador de aspersão. Boletim SBCTA, 1983; 17 (3): 235-254.

17. Brasil. Ministério da Agricultura, Pecuária e Abastecimento. Portaria no. 146 de 07 de março de 1996. Regulamento técnico de identidade e qualidade de leite em pó. Diário Oficial da União, 1996. Mar. 11; Seção 1. Portuguese.

18. Madi LFC, Ortiz SAA, Mori EFG, Ferreira EEM, Pupo VL. Estudo da estabilidade e vida-de-prateleira do leite em pó integral. Boletim do Instituto de Tecnologia de Alimentos, 1984; 21(3): 381-428.

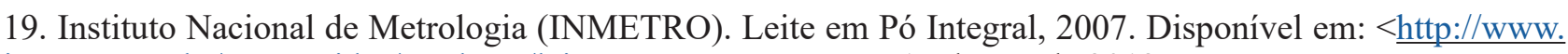
inmetro.gov.br/consumidor/produtos/leitepo.asp >. Acesso em: 15 de set. de 2012. 